\title{
PROGRAMA SALA DE LEITURA NO OESTE PAULISTA E A ATUAÇÃO DOCENTE: uma análise histórico-cultural
}

\author{
Homero Ferreira \\ Zizi Trevizan \\ Marcos Vinicius Francisco
}

Resumo

A Secretaria da Educação do Estado de São Paulo, a partir do ano letivo de 2009, implantou o Programa Sala de Leitura em todas as escolas da rede estadual, por considerá-las como espaços privilegiados de incentivo à leitura, fonte de informação, entretenimento e formação do leitor crítico, criativo e autônomo. O objetivo desta pesquisa foi verificar a identidade profissional, a formação docente e as práticas de mediação no Programa Sala de Leitura. Foram analisados os impactos do Programa na atuação docente, em três escolas públicas de uma cidade do oeste paulista. Foi assumida a abordagem qualitativa de pesquisa, do tipo estudo de caso, na perspectiva histórico-cultural bakhtiniana. A coleta dos dados centrou-se na análise documental e em entrevistas semiestruturadas com três docentes, responsáveis pela Sala de Leitura. Os resultados apontaram tanto o entusiasmo das docentes e o acesso a livros, revistas e jornais, possibilitado pelas ações de estimulação da leitura, como também as fragilidades nas condições ofertadas pelo Estado, que comprometeram a atuação mediadora dessas profissionais.

Palavras-chave: programa paulista sala de leitura; ação docente; processos histórico-culturais.

\section{READING ROOM PROGRAM OF THE WEST SÃO PAULO AND THE TEACHING ACTION: a historical-cultural analysis}

\begin{abstract}
The São Paulo State Department of Education, as of the 2009, implemented the Reading Room Program in all schools in the education system, considering them as privileged spaces to encourage reading, a source of information, entertainment and formation of the critical, creative and autonomous reader.The objective of this research was to verify the professional identity, teacher training and mediation practices in the Reading Room Program. The impacts of the Program on the teaching performance were analyzed in three public schools in a city in western São Paulo. The qualitative research approach, of the case study type, was assumed in the Bakhtinian historical-cultural perspective. Data collection focused on documentary analysis and on semi-structured interviews with three teachers, responsible for the Reading Room. The results pointed out both the enthusiasm of teachers and access to books, magazines and newspapers, made possible by the actions of stimulation of reading, as well as weaknesses in the conditions offered by the State, which compromised the mediating performance of these professionals.
\end{abstract}

Keywords: paulista program reading room; teaching action; historical-cultural processes. 


\section{EL PROGRAMA PARA LA LECTURA DE OESTE PAULISTA Y LAS ACTIVIDADES DE ENSEÑANZA: \\ un análisis histórico-cultural}

\section{Resumen}

El Departamento de Educación del Estado de São Paulo, a partir del año escolar 2009, implementó el Programa de Sala de Lectura en todas las escuelas de la red estatal, considerándolos como espacios privilegiados para fomentar la lectura, una fuente de información, entretenimiento y formación del lector crítico, creativo y autónomo. El objetivo de esta investigación fue verificar la identidad profesional, la capacitación docente y las prácticas de mediación en el Programa de la Sala de Lectura. Los impactos del Programa en el rendimiento de la enseñanza se analizaron en tres escuelas públicas de una ciudad en el oeste de São Paulo. El enfoque de investigación cualitativa, del tipo de estudio de caso, se asumió en la perspectiva histórico-cultural de Bakhtin. La recopilación de datos se centró en el análisis documental y en entrevistas semiestructuradas con tres profesores, responsables de la Sala de Lectura. Los resultados señalaron tanto el entusiasmo de los docentes como el acceso a libros, revistas y periódicos, posibilitados por las acciones de estimulación de la lectura, así como las debilidades en las condiciones ofrecidas por el Estado, que comprometieron el desempeño mediador de estos profesionales.

Palabras clave: programa sala de lectura paulista; acción docente; procesos histórico-culturales.

\section{INTRODUÇÃO}

O texto deste artigo resultou de uma pesquisa em nível de mestrado; por meio dela, foram analisados os impactos do Programa ${ }^{1}$ Sala de Leitura do Estado de São Paulo na atuação de três docentes, responsáveis pelos Projetos nas Salas de Leitura, em três escolas públicas de uma cidade de médio porte do oeste paulista. As escolas foram as primeiras inseridas, no referido município, no Programa Estadual de Ensino Integral. Essas escolas seguem as diretrizes desse Programa, com base na Resolução n. 15 de 18/12/2009 (SÃO PAULO, 2009) e Resolução n. 60 de 30/08/2013 (SÃO PAULO, 2013). Esses documentos, "fonte natural de informação" (LÜDKE, ANDRÉ, 1986, p. 39) se vinculam a um contexto relevante para a análise dos dados coletados.

A problematização levou em consideração que, para se ter o estudante leitor proficiente, é preciso haver o professor leitor, igualmente proficiente - capaz de compreender e fazer compreender as funções dos signos de significar e de representar a realidade. No processo de significação, os signos se relacionam entre si, nas estruturas frásicas (internas) do texto. E, na representação, os signos se relacionam com os seus usuários (autor/leitor), fazendo emergir a realidade pragmático-social, implícita nas estruturas transfrásicas do texto.

Tal reconhecimento duplo das funções de significar e de representar dos signos é ressaltado pela teoria histórico-cultural, que, no processo de elaboração dos significados de um texto, enfatiza a relevância do processo dialógico e ambivalente (BAKHTIN, 2014), estabelecido por uma sintonização cultural do leitor com o autor, seres sociais contextualizados em determinado tempo e espaço.

Considerando a diversidade de usos dos signos em diferentes gêneros textuais, explorados no Programa Sala de Leitura (jornais, revistas e não só os textos didáticos/paradidáticos), a pesquisa sobre a formação das docentes (responsáveis pelas Salas de Leitura) partiu da hipótese de elas não terem sido preparadas, epistemológica e pedagogicamente, para o exercício do ensino de leitura de

\footnotetext{
${ }^{1}$ É necessário explicitar as diferenças entre Programa e Projetos. O Programa Sala de Leitura foi elaborado pela Secretaria Estadual de Educação de São Paulo, enquanto que Projetos referem-se às ações desencadeadas pelas participantes em cada uma das Salas de Leitura, nas escolas onde se encontram inseridas.
} 
diferentes modalidades textuais e de não terem, inclusive, recebido do próprio Estado as condições desejáveis para uma formação teórica específica e práticas de mediação, necessárias a um bom desempenho profissional.

Assim, os questionamentos que instigaram o desenvolvimento da pesquisa foram: Qual a formação leitora dessas três professoras, responsáveis pelas Salas de Leitura? Em suas graduações, pós-graduações ou, ainda, por meio de programas estaduais, foram preparadas para o trabalho com a leitura? Suas formações se restringiram ao uso passivo de livros ou materiais didáticos ofertados pela Rede Estadual? E, sobretudo, qual o embasamento teórico-epistemológico do ensino (sugerido por elas) nesse Programa de trabalho com a leitura?

O estudo, de natureza qualitativa, do tipo estudo de caso, ancorou-se a partir dos pressupostos histórico-culturais da teoria da filosofia materialista da linguagem (BAKHTIN, 2002, 2014).

As características da pesquisa qualitativa, pontuadas por Lüdke e André (1986), levam em conta o ambiente natural que, nessa investigação, foram três escolas e a Sala de Leitura. Foi assumida a tipologia do estudo de caso, no qual a pesquisa é caracterizada pelo interesse de casos individuais (STAKE, 2009). Lüdke e André (1986) apresentam, como elementos fundamentais do estudo de caso, a descoberta, a interpretação no contexto natural, o retrato da realidade, a variedade de fontes de informação, as generalizações resultantes da experiência de vida diária, os diferentes e conflitantes pontos de vista e a descrição em linguagem mais acessível.

$\mathrm{Na}$ prática do estudo de um caso típico, como o desta pesquisa, voltado a um Programa específico, que ocorre em 5,3 mil escolas do estado paulista, a possibilidade de generalização interessa ao pesquisador como forma de contribuição e expansão dos resultados obtidos. "Isso é muito claro, já que o interesse se volta para a investigação sistemática de uma instância específica" (LÜDKE, ANDRÉ, 1986, p. 23); circunstância em que se enquadra o Programa Sala de Leitura. A escolha das três escolas se deu pelo fato de, até então, elas serem as únicas (do município selecionado para a investigação) inseridas no Programa de Ensino Integral, pelo qual a dedicação do professor - integral e exclusiva - possibilita mais tempo à Sala de Leitura, em relação às demais escolas.

Os procedimentos utilizados na coleta de dados centraram-se na entrevista semiestruturada e na análise documental. Conforme Triviños (1987, p. 146), a entrevista semiestruturada parte de "[...] questionamentos básicos, apoiados em teorias e hipóteses que interessam à pesquisa" e oferecem "[...] amplo campo de interrogativas", resultantes de "[...] novas hipóteses que vão surgindo à medida que se recebem as respostas" dos participantes. As entrevistas ocorreram nas próprias unidades escolares e tiveram duração aproximada de uma hora. O material coletado por meio das entrevistas foi gravado e transcrito. Essa modalidade de procedimento viabilizou a possibilidade de indagações mais amplas e o contato direto - o que ampliou o campo da comunicação (pesquisadores $\mathrm{x}$ três professoras responsáveis por Projetos vinculados ao Programa Sala de Leitura). A análise documental permitiu a contextualização dos dados das entrevistas.

No processo de interpretação dos dados coletados dos documentos (Resolução n. 15, 2009; Resolução n. 60, 2013) e das entrevistas, foram analisados e caracterizados os assuntos abordados, agrupando-os por significados temáticos. O confronto estabelecido entre os pressupostos epistemológicos da pesquisa e os dados coletados foi explorado em dois eixos: o da descrição analítica e interpretativa do Programa Sala de Leitura via contato com os documentos que fundamentaram o mesmo, e o da descrição analítica e interpretativa dos conteúdos obtidos por meio das entrevistas com as participantes. Tal confronto possibilitou o alcance do objetivo geral do estudo de verificar a identidade profissional, a formação docente e as práticas de mediação no Programa Sala de Leitura. 


\section{A ATUAÇÃO DOCENTE NO ENSINO DE LEITURA: CONTRIBUIÇÕES DA TEORIA HISTÓRICO-CULTURAL BAKHTINIANA}

Não basta interação física e ensino conteudista para a formação de um estudante leitor. Numa perspectiva histórico-cultural, de comprometimento social e de responsabilidade ética e humana, o ensino une o estudante ao professor (sujeitos históricos) e, ambos, ao produto cultural (texto/discurso), resultante de uma situação social que lhe dá origem política, ideológica, funcional. Em outros termos, sujeitos (autor x leitor) e situação sócio-histórica são determinantes, na leitura, da significação de um texto, como já havia anunciado Bakhtin (2014), no processo contributivo de avanços linguísticos sobre as concepções teóricas de texto; do que é a língua, a fala e linguagem; e a relevância desses conceitos para a definição bakhtiniana de leitura dialógica e ambivalente.

Segundo Trevizan (2017, p. 246), diferentemente de Saussure, que priorizava a língua e desconsiderava a linguagem, Bakhtin elegeu a linguagem na sua natureza compósita e indissociável (língua $\mathrm{x}$ fala) como objeto central de suas investigações. Em outros termos, para o autor da filosofia materialista da linguagem, a "[...] língua vive e evolui historicamente na comunicação verbal concreta, não no sistema linguístico abstrato das formas da língua, nem no psiquismo individual dos falantes" (BAKHTIN, 2014, p. 128).

Em razão desta diferença teórica, Bakhtin (2014) utilizou a obra fundamental do linguista clássico Ferdinand de Saussure, Curso de Linguística Geral (1. ed. 1916) como objeto de crítica contundente à tendência linguística clássica, sincrônica, que separava a língua da fala, por privilegiar a primeira (língua) como objeto único de estudo. Afirma Trevizan (2017, p. 247) que Bakhtin, portanto, não excluiu a corrente teórica do "objetivismo concreto" centrado no estudo da língua como propunha Saussure, mas a incluiu no diálogo necessário com a teoria do "subjetivismo idealista", para uma valorização do ato individual da fala, propondo, portanto, "a síntese dialética" definidora do seu conceito de linguagem: língua $\mathrm{X}$ fala.

Dessa forma, utilizando-se da filosofia materialista da linguagem, Bakhtin (2014) enfatiza a função sociológica do texto, ou seja, seus sentidos pragmático-sociais. Para Bakhtin (2014, p. 16), a filosofia marxista da linguagem deve colocar como base de sua doutrina a "enunciação" como "realidade da língua" e, também, como "estrutura sócio-ideológica".

Trevizan (2002) esclarece, por exemplo, que se o professor adotar previamente uma concepção redutora de texto, de suporte teórico-linguístico saussureano, por conceber o texto como um ato de lingua (e não de linguagem) pode condicionar, na prática escolar, um procedimento metodológico, igualmente redutor, de leitura superficial dos sentidos literais do texto. A autora enfatiza que uma concepção histórico-cultural de texto de suporte bakhtiniano pode conceber a leitura como resultado de um ato dialógico (complexo) entre autor e leitor, manifestado pela linguagem. Tal concepção conduzirá, igualmente, à prática escolar de uma leitura ambivalente de reconhecimento da relevância do contexto na determinação de significados (culturais) do texto, que não se limitarão, portanto, à identificação dos sentidos linguísticos de uma semântica construída nas relações dos signos no texto, ou seja, pelas relações gramaticais firmadas morfológica e sintaticamente.

Bakhtin (2014) considera que a leitura envolve essa complexidade de relações linguísticas, psicológicas e sociais que emergem dos signos de um texto, vinculado a um contexto históricocultural, determinante da significação dos mesmos. Sendo assim, na concepção bakhtiniana, os sentidos manifestados linguisticamente no texto e, ao mesmo tempo, os sentidos implícitos na rede dos signos vinculados ao autor e leitor, inseridos em determinados contextos, é que levam à configuração da significação total do discurso lido e ao reconhecimento final da sua coesão e de 
sua coerência, portadoras da complexidade dos seus significados pragmáticos e sociais de caráter ideológico.

Nesse sentido, Bakhtin (2002) diz que a língua não pode ser compreendida isoladamente, fora do seu contexto social. $\mathrm{O}$ autor destaca a importância dos elementos extralinguísticos (transfrásicos) para compreensão dos atos (linguístico e social) de constituição dos sentidos do texto lido, ultrapassando a concepção clássica de língua como um sistema (fechado) de leis linguísticas.

Ainda no que tange ao estudo sobre a compreensão de textos, Kleiman (2008) descreve vários aspectos que constituem a leitura; destaca a complexidade do ato de compreender e a multiplicidade dos processos cognitivos necessários para o leitor obter a real percepção do texto e de seus vínculos culturais com o contexto de sua origem sociocultural. Para a autora, são os aspectos cognitivos, ampliados pelo reconhecimento da função social das linguagens, que levam à formação do leitor, enquanto intérprete crítico dos sentidos culturais do texto, situando-o, conscientemente, no contexto social da leitura, como agente transformador.

Assim, o ler para "dar vida aos livros", conforme Failla (2012, p.20), vai muito além do abastecimento ou aparelhamento das escolas com obras diversas. À escola, como centro de formação de leitores, cabe, por intermédio do trabalho docente, estimular os estudantes a lerem e a torná-los conscientes de que compreender o que é lido envolve o reconhecimento da função social do texto (ensino da linguagem verbal e das linguagens não verbais).

\section{CONTEXTUALIZAÇÃO HISTÓRICA DO PROCESSO DE IMPLANTAÇÃO DO PROGRAMA PAULISTA SALA DE LEITURA E CONDIÇÕES DE INFRAESTRUTURA NECESSÁRIAS AO SEU FUNCIONAMENTO}

No âmbito do discurso governamental, as medidas adotadas para a criação e funcionamento do Programa Sala de Leitura alcançaram todas as unidades escolares da rede estadual de São Paulo, sendo a Sala de Leitura destinada aos estudantes da referida rede. Essa é considerada espaço privilegiado de incentivo à leitura como fonte de informação, entretenimento e formação do leitor crítico, criativo e autônomo. Foi estabelecido, no processo de implantação do Programa, um cronograma gradativo, com início a partir do ano letivo de 2009, de acordo com vários critérios, dentre os quais, o espaço e o acervo da escola interessada. Para cada escola, a implantação dependeu da publicação de autorização da Coordenadoria de Estudos e Normas Pedagógicas, da Secretaria de Educação do Estado de São Paulo.

O documento oficial instituiu a figura do professor responsável, com preferência para o formado em Letras e com experiência docente de, no mínimo, três anos no quadro do magistério da Secretaria de Estado da Educação (SÃO PAULO, 2014). A seleção e indicação desse professor couberam ao diretor da escola, atribuindo a ele carga de 40 horas semanais, sendo 33 de atuação na Sala de Leitura, 03 Horas de Trabalho Pedagógico Coletivo (HTPCs) e 04 Horas de Trabalho Pedagógico de Livre Escolha (HTPLs). Conforme o apurado pela pesquisa, nas três escolas, apenas uma das professoras tem a formação inicialmente exigida. Entretanto, consta, no mesmo documento, que, na falta do profissional com formação específica, pode ser professor responsável qualquer outro que se encaixe apenas no tempo mínimo de docência exigido. Além da professora de Letras, a pesquisa identificou duas docentes, uma com Pedagogia e outra com Psicologia, nas condições específicas de professoras responsáveis por salas de leitura.

Também foi identificado, na análise desse documento (SÃO PAULO, 2014, p. 11) que o Programa Ensino Integral propõe uma "[...] escola alinhada com a realidade do jovem, preparando os alunos para realizar seu Projeto de Vida e ser protagonista de sua formação", a partir de "[...] 
uma jornada integral, com currículo integralizado, matriz flexível e diversificada"; e ainda, com uma infraestrutura específica: "[...] salas temáticas, sala de leitura, laboratórios de ciências e de informática", com professores/educadores em "Regime de Dedicação Plena e Integral à Unidade Escolar".

As diretrizes desse Programa enfatizam que, nessa lógica, será possível que os estudantes aprimorem suas competências e habilidades, a fim de que eles consigam sua inserção futura no mercado de trabalho, para o qual a leitura é uma exigência. "Nesse contexto, habilidades básicas como a de leitura e raciocínio já não são vistas, por muitos, como atributos humanos essenciais, mas sim como exigências que o mercado de trabalho coloca a alguns profissionais específicos" (SÃO PAULO, 2014, p. 18).

Bruno (2011) pondera que, embora o discurso governamental associe à educação a formação de jovens para o mercado de trabalho formal, poucos serão os contemplados nesse processo, já que o mesmo é estratificado e seletivo, acrescido ao fato de ser um mecanismo de controle social. A maioria dos jovens executará trabalhos simples que não exigem nível de complexidade e inovação ou comporão o contingente de reserva de mão de obra.

Complementa Kuenzer (2000, p.18), que, nesse contexto, retira-se do ensino médio o caráter de intermediação entre o ensino fundamental e a educação superior, promovendo, assim, uma formação profissional carente de uma sólida base de educação geral, com a ruptura entre uma "escola que ensine a pensar" e "uma escola que ensine a fazer", pelo "[...] domínio teóricometodológico do conhecimento socialmente produzido e acumulado" e pela "[...] memorização de procedimentos e do desenvolvimento de habilidades psicofísicas".

Ainda de acordo com as diretrizes do Programa (SÃO PAULO, 2014, p.1), cada escola tem sua sala de leitura, mantendo o estudante em seu próprio ambiente, sem que seja necessário se deslocar para uma biblioteca, geralmente a municipal. Outra proposição do programa faz referência ao "local e ambientes apropriados", justificando, também, a sala com móveis e equipamentos específicos em atendimento às finalidades das ações desenvolvidas com os estudantes.

No entanto, nas entrevistas com as três professoras, foi constatado que, em nenhuma das três escolas, havia móveis específicos ou planejados para ambiente de leitura, como o estado havia proposto; sendo que, em duas escolas, há dois computadores e uma impressora; em outra, falta impressora; em todas não há conexão à internet. Há, também, um movimento de iniciativa pessoal dessas docentes que se articulam para adquirir mais materiais para o desenvolvimento das atividades:

O Estado enviaria dois computadores e uma impressora. Mas não havia enviado até junho de 2015. Também não enviou o mobiliário [...] Há livros que os estudantes pedem muito, mas não temos [...] Estou esperando a liberação de verba para adquirir livros mais atuais [...] Os livros nem sempre são da literatura infanto-juvenil e o Estado tem enviado coleções (mais antigas), como as da série Vagalume [...] Os estudantes adoram histórias em quadrinhos, comprei alguns gibis e outros foram doados por eles. Também foi utilizado dinheiro da venda de papel, jornal e papelão (R \$30,00) (PARTICIPANTE A, 2015).

A Sala de Leitura possui dois computadores e uma impressora. Até junho deste ano (2015) não havia sido instalada internet e nem o mobiliário específico e tem escola com mobiliário próprio da Sala de Leitura, mas que não tem o Programa (PARTICIPANTE B, 2015).

A Sala de Leitura possui computador e impressora, mas não tem mobiliário específico. $\mathrm{O}$ acervo de livros não atende à demanda de determinadas obras. Por exemplo: são poucos os exemplares [...] apreciados pelos estudantes, [...] os existentes foram adquiridos por mim, com os recursos da comissão de venda dos 
produtos Avon, adquiridos por professores e funcionários da escola [...]. A obtenção de livros ocorre pelo Cadastro de Projetos Descentralizados, mas em 2015 (até junho), o governo não enviou (PARTICIPANTE C, 2015).

Essas falas revelam certo grau de precariedade do Programa, além de falhas de organização e funcionamento. É insustentável a iniciativa das professoras de adquirirem livros para os estudantes com recursos próprios. Nessa lógica, confirmou-se a desresponsabilização financeira do Estado em relação ao seu papel, mediante as pseudos justificativas de estar reduzindo custos desnecessários; aspectos esses que vêm contribuindo para o que se nomeia como degradação do ensino (BRUNO, 2011).

No que tange, ainda, às falhas de organização e funcionamento do programa, exemplificase que houve um lapso de tempo, de quatro anos, entre a sua criação (2009) e a publicação da Resolução sobre as atribuições dos professores responsáveis pelas salas de leitura, por meio da Resolução n. 60 de 2013 (SÃO PAULO, 2013).

Merecem destaque, ainda, quanto aos modos precários de formação das docentes e de organização e funcionamento da Sala de Leitura, as falas inadequadas das participantes, como por exemplo, a afirmação de que os livros enviados ao Programa "[...] nem sempre são de literatura infanto-juvenil". Como se sabe, crianças e jovens devem fazer leituras de diferentes conteúdos e linguagens, inclusive, de obras produzidas em distintos períodos históricos. Inadequações como essas, observadas nas falas das docentes, despertaram o objetivo de verificar a identidade profissional, a formação docente e as práticas de mediação semiótica no Programa Sala de Leitura, o que será discutido na sequência deste artigo.

\section{Formação e práticas de mediação das participantes da pesquisa}

A tabela 1 apresenta alguns dados que sintetizam a formação inicial das três professoras participantes da pesquisa, o tempo de atuação na docência, a atual condição trabalhista e o percurso de formação continuada.

Tabela 1- Perfil das docentes participantes da pesquisa

\begin{tabular}{|c|c|c|c|}
\hline Participantes: & A & B & C \\
\hline Formação / ano & $\begin{array}{c}\text { Psicologia / } \\
2000\end{array}$ & $\begin{array}{c}\text { Letras / } \\
1986\end{array}$ & $\begin{array}{c}\text { Pedagogia / } \\
1991\end{array}$ \\
\hline Instituição & Privada & Pública & Privada \\
\hline Idade / docência & $\begin{array}{c}36 \text { anos / } \\
16 \text { anos }\end{array}$ & $\begin{array}{c}50 \text { anos / } \\
27 \text { anos }\end{array}$ & $\begin{array}{c}48 \text { anos } / \\
23 \text { anos }\end{array}$ \\
\hline Condição & Efetiva & Efetiva & $\begin{array}{c}\text { Designada } \\
\text { Estável }\end{array}$ \\
\hline Pós-graduação & Não & $\begin{array}{c}\text { Duas } \\
\text { especializações }\end{array}$ & Sim \\
\hline Cursos / capacitação & Sim & Sim & Não \\
\hline $\begin{array}{c}\text { Experiência - } \\
\text { Coordenação / } \\
\text { Assessoria }\end{array}$ & Não & Não & Não \\
\hline Leciona atualmente: & Não & Não & Não \\
\hline Publicação & Não & Sim & \\
\hline
\end{tabular}

Fonte: Dados da Pesquisa, 2015. 
Sobre os procedimentos metodológicos adotados no ensino do ato de ler, nenhuma das professoras teve, durante a graduação, a oferta da disciplina Metodologia do Ensino de Leitura. Como disciplina de formação metodológica, a graduação em Letras proporcionou as disciplinas de Metodologia da Língua Portuguesa e de Metodologia da Língua Espanhola. Na Pedagogia, não houve oportunidade dessa formação. Na Psicologia, o entendimento da professora é o de que as disciplinas de Sociologia e Antropologia proporcionaram uma leitura de visão de mundo. Enfim, apenas a professora de Letras obteve conteúdos de ensino de Literatura Infantil. Sobre Linguagens Visuais, somente a pedagoga obteve instruções proporcionadas pela Diretoria Regional de Ensino (DRE) para atuar, durante algum tempo, numa sala de recursos, que consiste numa sala adaptada para atender estudantes com necessidades especiais. No ensino superior, nenhuma dessas três professoras teve a disciplina de Artes.

Para Trevizan (2017), um ensino de embasamento histórico-cultural, que conduza à formação do leitor crítico, é fundamental na formação docente; o aporte enfatiza a natureza histórico-cultural do signo, da significação, do texto e da leitura. No entanto, apenas a Participante C destacou que tal perspectiva chegou a ocorrer na sua formação, "em alguns cursos" de "capacitação rápida". É possível deduzir, dessa fala emitida e de outros discursos das outras duas professoras, que nenhum dos cursos de graduação (Psicologia, Letras e Pedagogia) ofertou esses saberes acadêmico-científicos, o que revela o nível insatisfatório das capacitações recebidas, para atuarem nas Salas de Leitura. Esse frágil conhecimento sobre os conteúdos teóricos, numa lógica de causa e efeito, resulta em consequências, ainda que não plenamente determinantes, mas com possíveis implicações e comprometimentos no processo de formação do estudante como leitor crítico.

No entanto, apesar de uma formação teórico-científica precária (sobre signo/ texto/ linguagem e leitura) há, nas professoras pesquisadas, um notável zelo pelas salas de leitura, bem arrumadas e organizadas em relação à manutenção do acervo e à disponibilização para a comunidade escolar, especialmente para os estudantes que têm liberdade em retirar livros das prateleiras, anotar a retirada em ficha específica de controle (sob o olhar das professoras responsáveis). Elas, em virtude do trabalho em regime de dedicação exclusiva, trabalham com flexibilidade de horário, o que permite atendimento aos estudantes no horário do almoço, servido na própria escola. Tal zelo e comprometimento das docentes com o Programa justificam, ainda mais, a relevância de uma formação teórico-científica capaz de lhes assegurar maior eficiência no desempenho profissional. Entretanto, suas falas continuam apontando a ausência de uma formação adequada para o ensino da leitura:

No ano passado (2014) os professores responsáveis pelo Programa [...] foram orientados somente sobre leitura. Como ler um conto e como trabalhar com ele. Neste ano (2015), as orientações têm sido sobre mediação e linguagem, com foco maior para as técnicas de filmagem, já que no Programa Sala de Leitura os alunos são estimulados a produzirem vídeos. A produção de vídeo é bem precária, com uma única câmera e sem outros recursos [...]. Ano passado a escola comprou equipamento de som (PARTICIPANTE A, 2015).

Oferece, com orientações técnicas nas abordagens de leitura. Isso ocorre nas capacitações ofertadas na Diretoria Regional de Ensino. São orientações dadas por especialistas, através de videoconferências. Existem também os momentos presenciais, envolvendo todos os professores que trabalham com a Sala de Leitura. Também acontecem os momentos de trocas de experiências, entre os professores (PARTICIPANTE B, 2015).

Quando entrei, em 2011, era trabalhada a questão da superação jovem. Estive em São Paulo para um curso de dois dias, no Centro de Referência em Educação 
Mário Covas. Fui instruída para postar atividades no Ambiente Virtual de Aprendizagem (AVA), objetivando postagem de relatos e troca de experiências. Porém, até junho de 2015 não tinha acesso ao AVA. A cada dois meses acontecem as capacitações, por videoconferência, na Diretoria Regional de Ensino [...] O tempo médio de duração é de 1 hora e meia. Ao final, são feitas discussões entre os participantes (PARTICIPANTE C, 2015).

Pelas falas das docentes, todas informaram ter recebido orientações técnicas, capacitações, mas apenas a Participante A declarou o recebimento de apoio de formação em leitura de contos e sobre "mediação e linguagem", mas com "foco" em técnicas de filmagem. A Participante C citou as orientações recebidas para "[...] postagem de atividades no Ambiente Virtual de Aprendizagem (AVA)". A Participante B falou de capacitações gerais ofertadas pelo Centro de Referência em Educação (CRE) Mário Covas, na Diretoria Regional de Ensino. Cumpre ressaltar que a Participante A é quem emitiu o conceito de texto, limitando-o à escrita; e o conceito de leitura como "compreensão da escrita", não se referindo a outras modalidades de linguagens, como as não verbais. As inquietações que surgem desses discursos são: como essas modalidades de capacitação, informadas por elas (a de refletir sobre mediação e linguagem, com o foco em "técnicas de filmagem", por exemplo), podem resultar em eficácia na formação e prática docente, se a professora (Participante A), além de não ter recebido saberes específicos da linguagem fílmica, também revelou, na sua fala, estar limitada em seu conceito de texto, a uma definição meramente linguística (verbal)? Dessa fala da Participante A e das formas de capacitação descritas por ela, pouco se pode esperar em relação a um progresso profissional de conhecimentos e práticas de trabalho com diferentes linguagens, a partir dessas modalidades formativas ofertadas pelo Estado.

De igual forma, a Participante $\mathrm{B}$, com relação à questão da formação continuada, afirma, de forma não esclarecedora, que a Diretoria Regional de Ensino oferece capacitações sobre "abordagens de leitura". Mas, quais abordagens foram indicadas? Qual a fundamentação teórica de embasamento dessas sugestões de abordagens de leitura? Enfim, se, na graduação, a formação foi precária, fica a percepção de que, na continuidade dessa formação, permanecem atos e comportamentos que não garantem a necessária criticidade da profissão docente (BARBOSA; BOLDARINE; NICÁSSIO, 2014). Tais aspectos coadunam com os apontamentos de Oliveira (2005, p. 36), já que "[...] para conhecer a realidade, não basta estar nela como uma garantia de já conhecê-la, pois se estaria permanecendo no mero nível da obviedade, já que a realidade não se limita ao imediatismo dado, pensado ou sentido".

A Participante $C$ faz, também, uma referência a sua formação continuada, às "capacitações por videoconferências" para o desenvolvimento de atividades de postagem no AVA. Fica, pois, claro, não só na sua fala, mas nas demais também, que os docentes continuam carentes de saberes teórico-científicos para o trabalho com textos de diferentes modalidades (DUARTE, 2015); e, no entanto, essas formas de capacitação ofertadas têm resultado, apenas, em procedimentos técnicos para realização de determinadas atividades igualmente técnicas (por exemplo: as de filmagens e as de depósito de informações no AVA), sem o prévio entendimento sobre conceitos e práticas de leitura de diferentes textos. Atos complexos de leitura são substituídos por atos mecânicos (técnicos) de determinadas atividades usuais nas escolas. São atos que ilustram os saberes científicos incompletos dos professores, pois não contemplam a significação complexa do texto, dialógica e ambivalente (BAKHTIN, 2014).

Diante da pergunta Os jornais e revistas foram utilizados em atividades complementares?, as respostas das entrevistadas foram:

Tem um dia da semana que ocorre o "Seja Atual". São disponibilizados para os alunos somente jornais e revistas, para estimular o hábito de ler. Muitos alunos 
não pegavam. Então, quando passaram a pegar foi preciso ensinar a encontrar as sessões, como as de esporte e política, por exemplo (PARTICIPANTE A, 2015). Por meio de temas, produzindo painéis com reportagens. Exemplo de temática: a Semana da Água ou a Abolição dos Escravos. Mas são somente os painéis, pois os professores também utilizam as publicações jornalísticas em suas disciplinas, sendo que algumas vezes tratam de questões mais densas, como bolsa de valores (PARTICIPANTE B, 2015).

Os professores utilizam na sala de aula. Tem aluno que lê na hora do almoço. Tem quem leva para casa, no final do dia. Nas aulas são utilizadas seções conforme a disciplina: língua portuguesa - crônicas e notícias; educação física esportes, geografia - regiões brasileiras, países, tempo e clima [...] No último curso, na Diretoria Regional de Ensino, foi trabalhada bastante a questão da imagem, mais para produção do que para leitura. Uma imagem é projetada no telão e os alunos vão dizendo o que é aquela imagem (PARTICIPANTE C, 2015).

Pelas falas, foram constatados os efeitos positivos do Programa, no que se refere à oferta de jornais e revistas aos estudantes, atendendo, assim, às recomendações teóricas de valorização da construção cultural do repertório intelectual, para um melhor desempenho social, enquanto leitores e produtores de textos. Mas, em relação à leitura de jornais e revistas, a discussão foi ampliada mediante o questionamento sobre os procedimentos de leitura voltados para uma descoberta dupla: a) a dos sentidos linguísticos firmados no texto; e b) a dos sentidos pragmático-sociais, apreendidos nas relações estabelecidas pelo diálogo do texto com o contexto social de sua origem (TREVIZAN, 2002). Sobre essas relações dialógicas que uma leitura deve estabelecer, assim se manifestaram as professoras:

É trabalhado o sentido social, com a atividade Cidadania da Semana. É lida uma notícia e feito o questionamento se o aluno já viveu aquela situação. São trabalhadas questões de preconceitos e valores. Um aluno obeso, que até cresceu as tetinhas, encontrou na Sala de Leitura momentos de discussões estimuladores da autoestima [...]. A leitura e a discussão ajudam muito. Não só ele, mas outros alunos que encontram, nas notícias e nas discussões, ajuda para suas diferenças (PARTICIPANTE A, 2015).

Existe trabalho em parceria do professor responsável pela Sala de Leitura com os professores das salas de aula. A parte de linguística fica com o professor de português. Na Sala de Leitura são trabalhadas questões de texto, da interpretação e do gênero. Não há tempo e nem espaço para trabalhar linguística na Sala de Leitura [...] (PARTICIPANTE B, 2015).

Dificilmente a gente recebe feedback do que ocorreu em sala de aula; apenas disponibilizando o material ao professor (PARTICIPANTE C, 2015).

Fica explícito o desconhecimento da leitura dos elementos linguísticos do texto (que constituem sua unidade de sentidos internos, gramaticais) e a leitura dos fatores externos (extralinguísticos), que constituem a coerência de sentidos ideológicos, resultantes da identificação, pelo leitor, do contexto histórico-cultural (do autor, do próprio texto e do leitor). Separar, na leitura do texto, o linguístico do histórico-cultural, constitui equívoco de profissionais não formados na área específica (Ciências da Linguagem) para essa modalidade de ensino. Por sua vez, a docente C revelou desconhecimento teórico e prático de ensino de leitura e se limitou a informar que ela só "disponibiliza o material ao professor".

Analisando-se os modos expostos pelas professoras, ficou claro que, na descrição dos usos feitos pela docente $\mathrm{A}$, predominou a preocupação com a discussão e reflexão sobre valores e 
preconceitos sociais implícitos nas notícias extraídas desses materiais, valorizando-se a leitura sociopragmática do texto. No entanto, a professora B revelou uma separação, indevida, do conteúdo linguístico (reservado ao professor de português), como se esse conteúdo não fizesse parte da "interpretação" do texto. Para Bakhtin (2014) a língua e a fala constituem a síntese dialética da linguagem de todo texto e se manifesta na e pela linguagem, no ato da leitura, tornando-se impossível separar a Linguística da Pragmática Social.

Barbosa et al. (2014, p. 149) afirmam que "[...] a preocupação com o ensino de leitura na escola tem razão de ser", considerando que a leitura, no âmbito da sociedade atual, "[...] é uma das ferramentas existentes para se pensar a inserção de pessoas num patamar de vida mais digno", remetendo a leitura como entendimento de mundo e apontando para a possibilidade de uma sociedade mais justa, e constituída, de fato, por leitores críticos. No entanto, quando questionadas se o Programa sugere uso de teorias como suporte epistemológico para a organização metodológica do ensino de leitura, a Participante A disse não se recordar; a Participante B ofereceu uma explicação mais ampla e a Participante $C$ foi sucinta:

Não me recordo. Uma teoria específica, não. É dado suporte pela capacitação e na troca de experiências, geralmente são copiadas as que deram melhores resultados de envolvimento e do aprendizado do aluno. Formação teórica, não. Aí é uma questão individual de cada professor [...] (PARTICIPANTE A, 2015). Os modos estão no Plano de Ação, que envolve a escola toda, e no Programa de Ação, específico da Sala de Leitura. Ambos devem responder em melhoria das avaliações internas e externas. Existem metas a serem alcançadas, registradas no PDCA, que é o Plan Do Check $A C T$, que vem da área empresarial e compreender planejar, checar e agir. A Escola de Tempo Integral segue os moldes do universo empresarial. Tudo que é feito tem que ser evidenciado através de fotos e documentos. [...] Existe uma monitoria bimestral, feita por supervisores da Diretoria de Ensino. As teorias sugeridas estão disponibilizadas no ambiente virtual do Centro de Referência em Educação Mário Covas, com vários links que remetem a autores sobre leitura e literatura [...] (PARTICIPANTE B, 2015).

É seguida a metodologia da escola de ensino integral, voltada para formar o aluno solidário, competente e autônomo. São trabalhadas as premissas desse tipo de escola (PARTICIPANTE C, 2015).

Pelas falas, nenhuma das participantes informou quais teorias sustentaram ou embasaram suas práticas educativas de leitura (autor, corrente, tendência). A professora B se restringiu a "ações" e "metas" do Programa e disse que "as teorias sugeridas" ficam disponibilizadas no sistema virtual do Centro de Referência em Educação Mário Covas (2009). No entanto, informou que essas teorias são referentes a questões sobre leitura/literatura e não expressou nenhum modelo pedagógico de ensino do ato de ler. A participante $\mathrm{C}$ mencionou a metodologia norteadora da Escola de Ensino Integral, voltada para a formação cidadã dos estudantes, mas não estabeleceu relação com as metodologias específicas de ensino de leitura. A Participante B, em sua fala, explicitou ainda o viés empresarial da Escola de Tempo Integral, iniciativa contestada por pesquisadores que entendem que a educação deva ocorrer pelo trabalho e não para o mercado de trabalho (DUARTE, 2015; KUENZER, 2000).

Portanto, as abordagens de conteúdos teóricos histórico-culturais não foram reveladas pelas docentes, professoras responsáveis pela Sala de Leitura, que carecem de tais conhecimentos, para compreensão mais ampla dos sentidos inter-relacionados nos diálogos entre autor, texto e o contexto da produção do texto. 


\section{CONSIDERAÇÕES FINAIS}

Confrontando, portanto, os pressupostos teóricos histórico-culturais, com os dados obtidos, pode-se afirmar que faltam saberes acadêmico-científicos (sobre língua/linguagem; texto e leitura) das docentes responsáveis pela Sala de Leitura e, consequentemente, esse desconhecimento interfere em suas práticas de formação de leitores. Embora tenha ocorrido forte estimulação para que os estudantes se envolvessem com a leitura, prevaleceram ações de leitura dos conteúdos dos textos, não se propondo a leitura específica das linguagens veiculadoras (ideológicas) desses conteúdos.

Nesse sentido, desfez-se a oportunidade de, no Programa, ocorrer uma maior valorização da função mediadora das docentes, pois essas se limitaram a ações genéricas de motivação e de inserção dos estudantes em ambientes físicos de leitura (escola e família), sem, contudo, procederem, num processo coletivo entre pares (docentes responsáveis pelas Salas de Leitura e docentes atuantes nas salas de aula), à leitura crítica e analítica dos livros.

Como comprovou a análise das falas das docentes, muitas vezes, a compreensão dessa responsabilidade chegou a se limitar ao ato simplista de repassar materiais e não de promover ações formativas dos jovens leitores, por meio das necessárias relações profissionais interpessoais, intra e intersubjetivas. A inexistência de interações verbais entre as próprias profissionais é reveladora, no processo escolar de construção cultural dos leitores críticos, dos impactos negativos do desconhecimento teórico das ciências da linguagem nas suas práticas de estimulação e ensino eficaz (crítico) da leitura. Enfim, o professor precisa do referencial teórico histórico-cultural, a partir do qual possa rever seus próprios saberes e reconstruir, continuadamente, seu cotidiano profissional, muitas vezes, impregnado de formações teóricas incompletas que levam a uma prática de leitura redutora e simplista, centrada apenas na decodificação linguística das relações sígnicas estabelecidas no texto.

Nessa perspectiva, assume-se como condição sine qua non na educação escolar, o estudo científico bakhtiniano da linguagem, relacionado à leitura como meio da formação da identidade histórico-cultural do leitor, centrada, sobretudo, na compreensão do texto não somente como unidade linguística verbal/ escrita, mas como uma comunicação social (contextualizada) que emana do exercício do diálogo da fala (advinda do subjetivismo idealista) com a língua (advinda do objetivismo abstrato), num processo complexo, dinâmico e histórico de produção de linguagens, ou seja, de formação dos repertórios culturais dos usuários (falantes da língua).

O Programa paulista Sala de Leitura, conforme o discurso oficial contido nas Resoluções n. 15 de 18/12/2009 e n. 60 de 30/08/2013, procura atender essa necessidade de concepção do ensino como um processo complexo de produção de linguagens, ofertando diferentes discursos, para o exercício da leitura e formação cultural do leitor. No entanto, os resultados da pesquisa em questão apontaram fragilidades nas condições de formação cultural e práticas que acabam comprometendo a atuação da mediação profissional das professoras responsáveis pela Sala de Leitura. É necessário esclarecer que, embora o Programa Sala de Leitura se encontre em vigência, a sua realidade pode ter se modificado nos últimos anos, já que a coleta dos dados, que geraram as conclusões dos pesquisadores, ocorreu em 2015. Tal esclarecimento se faz relevante, considerandose o perfil histórico-cultural desta investigação, que impõe a valorização de uma análise final focada na dimensão espaço-temporal dos dados coletados.

\section{REFERENNCIAS}

BAKHTIN, Mikhail. Estética da criação verbal. São Paulo: Martins Fontes, 2002. 
BAKHTIN, Michail/ VOLOCHINÓV, Valentin Nikoláievitch. Marxismo e filosofia da linguagem: problemas fundamentais do método sociológico da linguagem. Tradução de Michel Lahud e Yara Fratexchi Vieira. 16. ed. São Paulo: Hucitec, 2014.

BARBOSA, Raquel Lazzari Leite; BOLDARINE, Rosária de Fátima; NICÁSSIO, Rosemary Trabold Aprende-se a ler na escola: um estudo da aprendizagem de leitura na escola pública paulista. Todas as Letras X, São Paulo, v. 16, n. 2, p. 149-162, nov. 2014. Disponível em http://www.bibliotekevirtual.org/index.php/2013-02-07-03-02-35/2013-02-07-03-03-11/366letras/v16n02/3132-v16n02a12.html. Acesso em 19 jul. 2019.

BRUNO, Lúcia. Educação e desenvolvimento econômico no Brasil. Revista Brasileira de Educação, Rio de Janeiro, v. 16, n. 48, p. 545-562, set./dez. 2011. Disponível em http://www.scielo.br/scielo.php?script=sci arttext\&pid=S1413-

24782011000300002\&lng=en\&nrm=iso. Acesso em 14 ago. 2018.

CENTRO DE REFERÊNCIA EM EDUCAÇÃO "MÁRIO COVAS". Programa Sala de Leitura. 2009. Disponível em http://www.crmariocovas.sp.gov.br/ntc l.php?t=saladeleitura 04. Acesso em 15 mai. 2014.

DUARTE, Newton. A importância da concepção de mundo para a educação escolar: porque a pedagogia histórico-crítica não endossa o silêncio de Wittgenstein. Germinal: marxismo e educação em debate, Salvador, v. 7, n. 1, p. 8-25, jun. 2015. Disponível em https://portalseer.ufba.br/index.php/revistagerminal/article/view/12808/9501 Acesso em 13 ago. 2018.

FAILLA, Zoara. Retratos da leitura no Brasil 3. São Paulo: Imprensa Oficial, 2012.

KLEIMAN, Angela. Texto e leitor: aspectos cognitivos da leitura. 11. ed. Campinas: Pontes, 2008.

KUENZER, Acacia Zeneida. O ensino médio agora é para a vida: entre o pretendido, o dito e o feito. Educação \& Sociedade, Campinas, v. 21, n. 70, p. 15-39, abr. 2000. Disponível em http://www.scielo.br/scielo.php?script=sci_arttext\&pid=S0101-

73302000000100003\&lng=en\&nrm=iso. Acesso em 19 jan. 2019.

LÜDKE, Menga; ANDRÉ, Marli Eliza Dalmazo Afonso de. Pesquisa em educação: abordagens qualitativas. São Paulo: EPU, 1986.

OLIVEIRA, Betty. A dialética do singular-particular-universal. In: ABRANTES, Angelo Antônio; SILVA, Nilma Renildes da; MARTINS, Sueli Terezinha Ferreira. Método histórico social na psicologia social. Petrópolis: Vozes. 2005. p. 25-51.

SÃO PAULO (Estado). Resolução SE n. 15, de 18 de fevereiro de 2009. Dispõe sobre a criação e organização de Salas de Leitura nas escolas da rede estadual de ensino.

Disponível

em

http://siau.edunet.sp.gov.br/ItemLise/arquivos/15 09.HTM?Time=19/07/2019\%2011:21:22

Acesso em 14 ago. 2015.

SÃO PAULO (Estado). Resolução SE n. 60, de 30 de agosto de 2013. Dispõe sobre a atuação do professor em sala/ambiente de leitura, nas escolas estaduais no Programa Ensino Integral, e dá providências correlatas. Disponível em http://siau.edunet.sp.gov.br/ItemLise/arquivos/60_13.HTM?Time=19/07/2019\%2011:24:05 Acesso em 14 ago. 2015.

SÃO PAULO (Estado). Secretaria de Educação do Estado de São Paulo. Programas e Projetos. 2014. Disponível em http://www.educacao.sp.gov.br/portal/projetos. Acesso em 02 jan. 2015. 
SAUSSURE, Ferdinand. Curso de linguística geral. 27. ed. São Paulo: Cultrix, 2006.

STAKE, Robert E. A arte de investigação com estudos de caso. 2. ed. Lisboa - PT: Fundação Calouste Gulkenkian, 2009.

TRIVIÑOS, Augusto Nibaldo Silva. Introdução à pesquisa em ciências sociais: a pesquisa qualitativa em educação. São Paulo: Atlas, 1987.

TREVIZAN, Zizi. O leitor e o diálogo dos signos. 3. ed. São Paulo: Clíper Editora, 2002.

TREVIZAN, Zizi. Saberes científicos e epistemologia da prática nos processos institucionais de formação docente e de formação de leitores. Perspectiva, Florianópolis, v. 35, n. 1, p. 237-261, jan./mar. 2017.

Disponível em https://periodicos.ufsc.br/index.php/perspectiva/article/view/2175-795X.2017v35n1p237/pdf Acesso em 19 jul. 2019.

\section{Informações dos(a) autores(a)}

Homero Ferreira

Universidade do Oeste Paulista (Unoeste). Professor do curso de Comunicação Social

E-mail: homero@unoeste.br

ORCID: http://orcid.org/0000-0002-5090-2294

Link Lattes: http://lattes.cnpq.br/5377143005296604

Zizi Trevizan

Universidade Estadual Paulista (UNESP), Campus de Presidente Prudente/ Docente aposentada E-mail: zizitrev@uol.com.br

ORCID: http://orcid.org/0000-0002-7063-2455

Link Lattes: http://lattes.cnpq.br/2967248644893507

Marcos Vinicius Francisco

Universidade do Oeste Paulista (Unoeste). Docente do Programa de Pós-Graduação em Educação; Universidade Estadual de Maringá (UEM). Docente do Programa de Pós-Graduação em Educação E-mail: marcos_educa01@yahoo.com.br

ORCID: http://orcid.org/0000-0002-5410-2374

Link Lattes: http://lattes.cnpq.br/7996858773030239 